\title{
Emergy-based study on eco-economic system of arid and semi-arid region: a case of Gansu province, China
}

\author{
Bing XUE ${ }^{1,2^{*}}$, XingPeng $\mathrm{CHEN}^{2}$, Yong GENG ${ }^{1}$, Mian YANG ${ }^{2}$, FuXia YANG ${ }^{3}$, XiaoFen $\mathrm{HU}^{2}$ \\ ${ }^{1}$ Circular Economy and Industrial Ecology Group, Key Laboratory of Pollution Ecology and Environmental Engineering, Institute \\ of Applied Ecology, Chinese Academy of Sciences, Shenyang 110016, China; \\ ${ }^{2}$ College of Earth and Environmental Sciences, Lanzhou University, Lanzhou 730000, China; \\ ${ }^{3}$ School of Economy, Lanzhou University, Lanzhou 730000, China
}

\begin{abstract}
Taking Gansu province as a model case, this study provides an integrated analysis on the eco-economic system of arid and semi-arid region based on emergy synthesis theory. Through calculating the values of renewable emergy flow, non-renewable resources, imported emergy, exported emergy, waste emergy, and total emergy during the period of 1978-2007, the performance of Gansu eco-economic system was analyzed. The results indicated that the renewable emergy flow within the province basically remained steady state which was estimated at $2.99 \times 10^{22}$ solar emjoules (sej) from 1978 to 2007 . The imported emergy and exported emergy were estimated at $3.75 \times 10^{17}$ sej and $2.99 \times 10^{20}$ sej in 1978 and increased to $1.07 \times 10^{22}$ sej and $1.44 \times 10^{22}$ sej respectively in 2007 . The nonrenewable emergy flow was estimated at $1.62 \times 10^{22}$ sej and increased to $1.85 \times 10^{23}$ sej, with annual growth rate of $8.7 \%$, while the estimated total emergy was $4.58 \times 10^{22}$ sej in 1978 and increased to $2.11 \times 10^{23}$ sej in 2007 , with annual growth rate of $5.41 \%$. Our results indicate a deteriorate situation between economic development and environmental protection in the region. The rapid economic growth in the past thirty years was based on a great consumption of nonrenewable resource and caused continuous decrease in the capacity of sustainable development. The environmental loading ratio was 0.53 in 1978, increased to 6.06 in 2007, indicating a rapid degradation of the regional environment quality. We calculated that the actual population was 1.53 times the renewable resource population in 1978, increased to 7.06 times in 2007. During the period of 1978-2007, the emergy rose from $2.45 \times 10^{15} \mathrm{sej} /\left(\right.$ capita.a) to $8.07 \times 10^{15} \mathrm{sej} /($ capita.a). Our analysis revealed that the emergy density presented a trend of gradual increase, and then the emergy currency ratio in Gansu decreased from $7.08 \times 10^{13}$ sej/Chinese Yuan to $7.82 \times 10^{12}$ sej/Chinese Yuan.
\end{abstract}

Keywords: emergy analysis; economic geography; regional sustainable development; arid and semi-arid area; Gansu province

\section{Introduction}

There were extensive researches on the topic of economic growth and environmental protection. In most developing areas around the world, our choices to protect or exploit the environment have been determined by economic standard and scarce natural resources (Bartoszczuk and Nakamori, 2003). Generally, the methods of studying regional eco-economic system include material flow and energy flow accounting. Emergy analysis, one of the energy accounting methods, aims to fully integrate the values of energy, material and information in a common unit within a system, was first presented by Odum, out of a creative combi- nation of energetic and systemic ecology (Odum, 1988; Jiang et al., 2008). Emergy is a measure of the real resources supplied by nature to the investigated system (directly or through societal processes), estimated on a common basis, namely that of the biosphere (Odum and Odum, 2006). Emergy accounts for both the free environmental and purchased inputs that constitute the direct and indirect support of human activities. The emergy of all inputs to a system is calculated in terms of solar emjoules (sej) by means of suitable conversion factors called transformities (sej/J or sej/g)

Received 2009-11-11, accepted 2010-05-18

doi: 10.3724/SP.J.1227.2010.00207

* Corresponding author: Bing Xue (E-mail: xuebing @iae.ac.cn) 
which can be calculated and compared with other energy forms. The solar transformity of services and products, generated by the system, is obtained by dividing the total emergy input required by the energy of the product or service (Odum, 1988).

The method can bridge the gap between socio-economic development and the environmental protection that sustains the development, and can provide a single unit of measurement that accounts for material, energy, and monetary flows within human-nature system (Patten, 1992; Odum, 1997; Brown and Buranakarn, 2003). Other scholars have used this evolving theory to study the eco-economic system of Taiwan (Huang and Odum, 1991), energy use, environmental loading and sustainability analysis of Italy (Ulgiati et al., 1994), a compound agro-ecosystem in the Taihu Lake area of China (An et al., 1998), the biosphere and natural capital (Brown and Ulgiati, 1999), a multipurpose dam proposal in Korea (Kang and Park, 2002) and other economic developmental activities. In emergy analysis, the quality of each form of energy is taken into account by multiplying each flow of energy and matter by its solar transformity. Transformity is defined as the quantity of one type of emergy required to generate a unit of energy of another type. Emergy synthesis can quantify or place a value on the material, energy, and monetary flows in a regional eco-economic system by applying the appropriate transformities (Brown and Ulgiati, 2004; Zhang et al., 2009).

Solar energy is the primary source that feeds all processes and cycles found on Earth. Traveling backwards in the history of the thermodynamic transformations of energy, it is possible to perform an analytic calculation of the content of solar energy 'stored' in every natural resource. Therefore, emergy is a sort of memory of the solar energy that has been used in order to obtain a given product or flow through a series of transformations. This memory is associated with the effort that nature executed in order to make a given resource available (Odum, 1996; Brown and Ulgiati, 2004; Chen and Chen, 2009).

Arid and semi-arid regions covers a land area of $5.04 \times 10^{6} \mathrm{~km}^{2}$, accounting for $52.5 \%$ of that of China. Broad scale environmental degradation has occurred throughout arid and semi-arid regions of China over the past century. Most of the changes were caused by the impacts of human activities (Chen et al., 2005; Ma et al., 2005; Li et al., 2008). In the past 30 years after China adapted an open polices, there are significant changes in the social life styles, living standards and environment. However, there is a lack in the integrated analysis on how a rapid change of the society presents challenges to regional sustainable development. In this paper, by taking Gansu province as an example, we adapted the emergy analysis approach to account the energy, materials, and money flows within regional eco-economic system. Our aims are to figure out the system characters to the society impacts which may help to facilitate the regional sustainable development.

\section{Study area and methods}

\subsection{Study area}

Gansu province is located in northwest of China. It is about $1,520 \mathrm{~km}$ in its length from east to west, 1,655 $\mathrm{km}$ in its widest region and only $25 \mathrm{~km}$ in the narrowest region. The province is a typical province located in the arid and semi-arid region of China (Fig. 1).

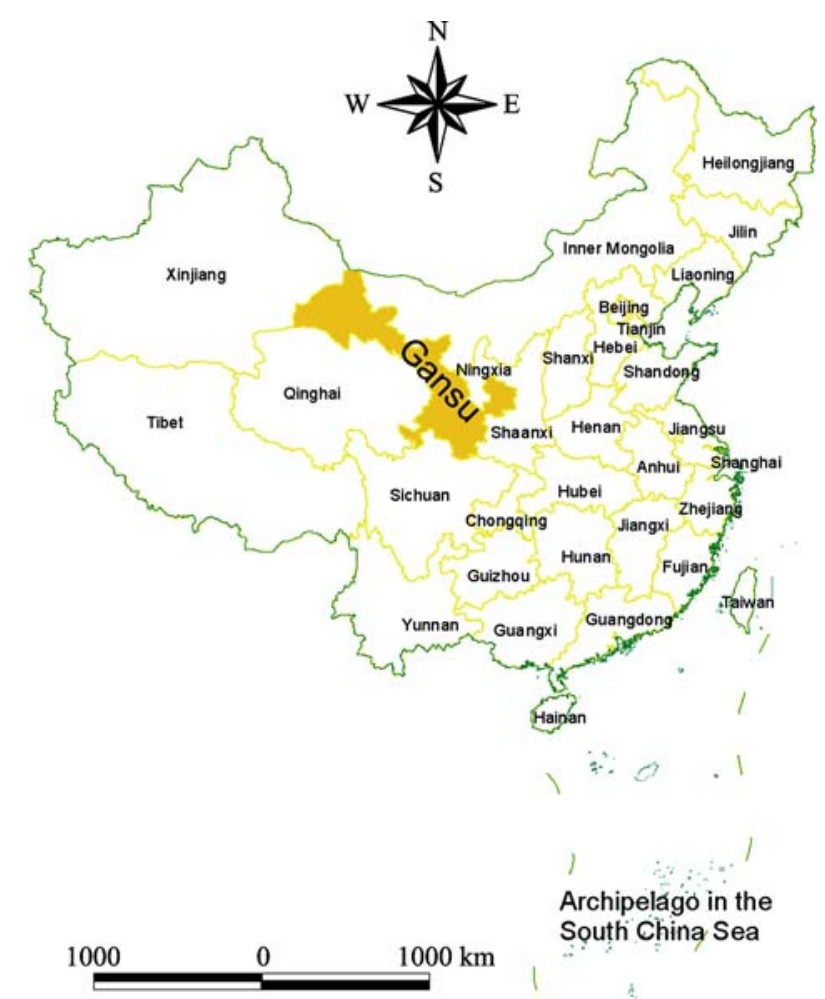

Fig. 1 Sketch map of Gansu province 
The landforms in Gansu are complicated and diverse. There are 450 rivers, among which 78 rivers have a yearly runoff of over $1 \times 10^{8} \mathrm{~m}^{3}$. Gansu has a dry climate with plenty of sunshine, strong radiation. The annual average temperature is $8.8^{\circ} \mathrm{C}$ and the annual evaporation is $1,578 \mathrm{~mm}$, while the annual precipitation is $447.3 \mathrm{~mm}$.

\subsection{Methods}

In the paper several emergy indicators defined by Odum (1996), Brown and Ulgiati (2004), including renewable emergy flow (R), non-renewable resources (N), imported emergy (IMP), exported emergy (EXP), waste emergy (W), total emergy used (U), environmental loading ratio (ELR), emergy self-sufficiency (ESR), net emergy yield ratio (NEYR), emergy density (ED), emergy per capita (EPC), and renewable resources population carrying capacity (RPC), were used to evaluate the eco-economic efficiency, the potential for environmental impacts from human activities, and the potential for sustainable development in the region, respectively (Table 1 ). There are detailed references for calculating emergy values of most energy and resources (Lan, 2002).

Most data used in this paper were citied from Gansu Statistical Yearbook (Gansu Yearbook Editorial Board, 1978-2008), and comprehensive statistical data and materials on 50 Years of New China (National Bureau of Statistics of China, 1949-1999).

Table 1 Emergy indicators for eco-economic system

\begin{tabular}{|c|c|c|}
\hline Indicators & Variable \& Expression & Unit \\
\hline Renewable Emergy Flow & $\mathrm{R}$ & sej/a \\
\hline Non-renewable Emergy Flow & $\mathrm{N}$ & sej/a \\
\hline Imported Emergy & IMP & sej/a \\
\hline Exported Emergy & EXP & sej/a \\
\hline Waste Emergy & $\mathrm{W}$ & sej/a \\
\hline Total Emergy Used & $\mathrm{U}=\mathrm{R}+\mathrm{N}+\mathrm{IMP}-\mathrm{EXP}$ & sej/a \\
\hline Environmental Loading Ratio & $E L R=(U-R) / R$ & --- \\
\hline Emergy Self-sufficiency & $\mathrm{ESR}=(\mathrm{R}+\mathrm{N}-\mathrm{EXP}) / \mathrm{U}$ & --- \\
\hline Net Emergy Yield Ratio & $\begin{array}{c}\mathrm{NEYR}=(\mathrm{R}+\mathrm{N}+\mathrm{IMP}) / \\
\text { IMP }\end{array}$ & --- \\
\hline Emergy Density & $\mathrm{ED}=\mathrm{U} /$ Area & $\mathrm{sej} / \mathrm{km}^{2}$ \\
\hline Emergy Per Capita & EPC $=\mathrm{U} /$ Population & sej/(capita·a) \\
\hline $\begin{array}{l}\text { Renewable Resources Popu- } \\
\text { lation Carrying Capacity }\end{array}$ & $\begin{aligned} \mathrm{RPC}= & (\mathrm{R} / \mathrm{U}) \times \\
& \text { Population }\end{aligned}$ & --- \\
\hline
\end{tabular}

\section{Results and discussion}

\subsection{General performance of the eco-economic system}

The emergy flows associated with the Gansu eco-economic system are summarized into six parts: renewable emergy flow (R), nonrenewable emergy flow (N), imported emergy (IMP), exported emergy (EXP), waste emergy (W), and total emergy used (U). The results were shown in Fig. 2. The renewable emergy flow basically remains steady state which was estimated at $2.99 \times 10^{22}$ sej during the period of 1978-2008. The nonrenewable emergy flow was estimated at $1.62 \times 10^{22}$ sej in 1978 and increased to $1.85 \times 10^{23}$ sej in 2007 , which is about $1.37 \%$ of that consumed in China $\left(1.35 \times 10^{25}\right.$ sej) (Jiang et al., 2008). Nonrenewable resources, mainly including metals, soil, and fossil fuels, have turned into the major impetus for the Gansu's economy. As shown in Fig. 2, the imported emergy increased from $3.75 \times 10^{17}$ sej to $1.07 \times 10^{22}$ sej while exported emergy increased from $2.99 \times 10^{20}$ sej to $1.44 \times 10^{22}$ sej during the period of 1978-2007, the change of imported emergy and exported emergy in Gansu are basically accorded with that of China (Yang et al., 2010). The total emergy used in Gansu province was $4.58 \times 10^{22}$ sej in 1978 and increased to $2.11 \times 10^{23}$ sej in 2007 , with annual growth rate of $5.4 \%$ (Fig. 2).

\subsection{Environmental evolution trend}

Environmental loading ratio is an indicator to reflect the health of an economic system in a region (Lan,

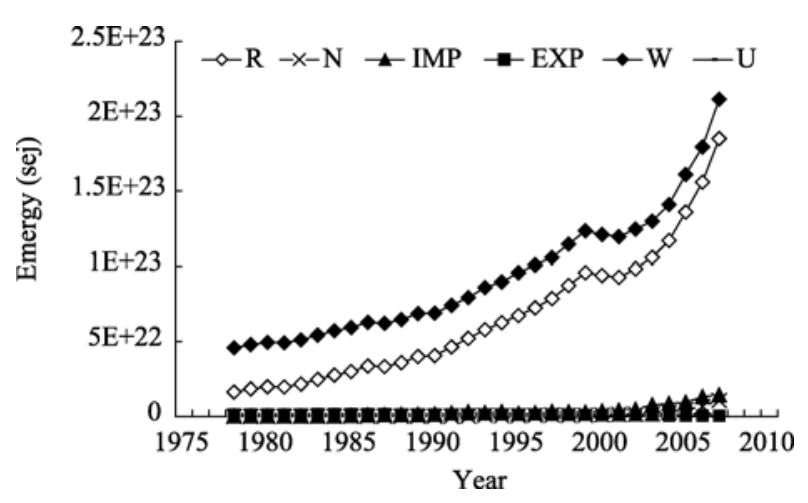

Fig. 2 Trend of emergy indicators (emergy flow (R), nonrenewable emergy flow (N), imported emergy (IMP), exported emergy (EXP), waste emergy (W), and total emergy used (U)) from 1978 to 2007 
2002). A high ratio indicates a degradation of a system. If the system is at high environmental loading ratio for a long time, it will form irreversible environmental function degeneration and comedown (Ulgiati et al., 1994; Ulgiati and Brown, 2009). The data were calculated from 1978 to 2007 for the region. It clearly shows that the environmental loading ratio presents an exponential ascending trend (Fig. 3). Particular, the environmental loading ratio increased up from 3 in 2000 to 6.06 in 2007, a rapid increase within the past thirty years. The slight decrease in the ratio from 1998 to 2001 was due to the decreased in devotion of nonrenewable resources.

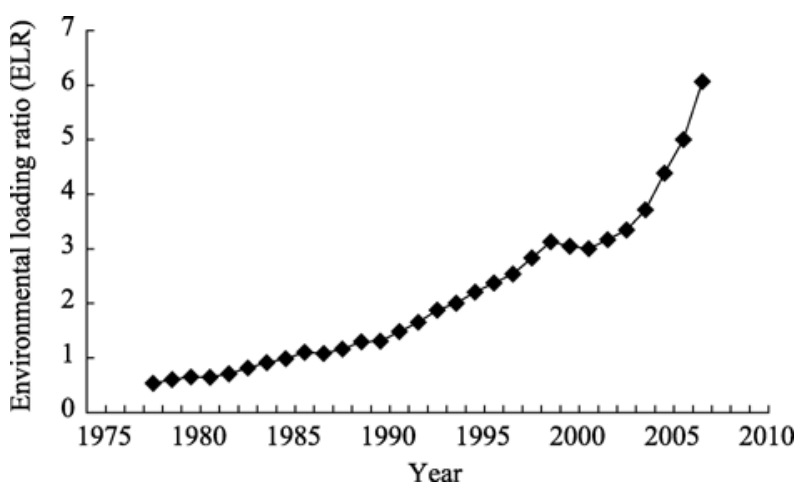

Fig. 3 Trend of environmental loading ratio (ELR) from 1978 to 2007

Compared with other regions around the world, the environmental loading ratio of Gansu province is higher than that in most of the developing countries. For example, Gansu region has the ratio of 6.00 in 2007, Brazil 0.75, Liberia 0.09, Papua New Guinea 0.15 , India 1.02, and the world average level is 1.15 . but the ratio in Gansu is lower than developed countries, such as Italy 9.47, Switzerland 7.44, Sweden 7.04 and Spain 7.2 (Jiang et al., 2008). Since a large ratio usually suggests a high technological level in emergy use as well as a high level of environmental stress, the high ratio indicates that the economic development of Gansu was intensively dependent on consuming of non-renewable resources and exerting great load to environment. In other words, along with the economic development, the economic activities were giving a high pressure to the environment, and there is little room for further sustainable development for Gansu province if following the same developmental model.
According to renewable resources population carrying capacity (RPC) of Gansu, and compared it with the actual population (AP), it is obvious that the gap between renewable resources population and the actual population were getting bigger and bigger (Fig. 4). Due to a fast population growth with an annual rate of about $1.12 \%$, the actual population was 1.53 times the renewable resources population carrying capacity in 1978, increased to 7.06 times in 2007. The renewable recourse with a high growth rate can bear the comparative bigger population of the equilibrium state, so, it is most important for the development of humans themselves to advance the growth rate of renewable resources.

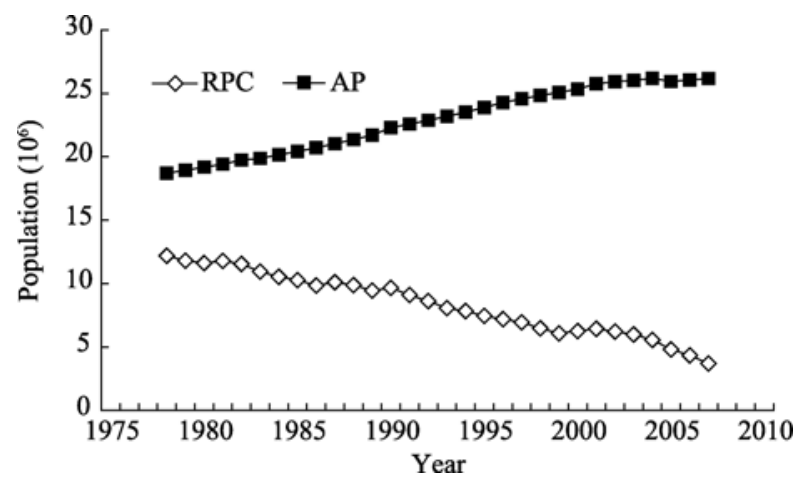

Fig. 4 Trend of renewable resources population carrying capacity (RPC) and actual population (AP) from 1978 to 2007

\subsection{Emergy-based economic indices of resources exploitation}

We also calculated the net emergy yield ratio (NEYR) for the region in thirty years and the results are presented in Fig. 5. The NEYR is an index that evaluates the contribution of the system yield to the economy. It is an indicator to show whether the basic energy and materials that supply to overall economic activities can satisfy the economic process (Ulgiati et al., 1994; Odum, 1997; Lan, 2002). We found that the NYER decreased dramatically from $1.23 \times 10^{5}$ in 1978 to 2.10 in 2007 (Fig. 5). The trend indicates that the economic system of Gansu largely based on the local resources consumption and export out flow, and less depended on resources imported from outside of the system. It also suggests that the economy of Gansu is very strong self-sufficient, may have strong potential and with limited influences from outside. On the other hand, it suggests that the economy is on low level with little 
innovations on science and technology. The regional economy is lack of competitive capability either intersectional or international. However, such economic system presents a high pressure to the regional environment. In a long run, the economy will be confronted with high challenges while influenced by external economic activities.

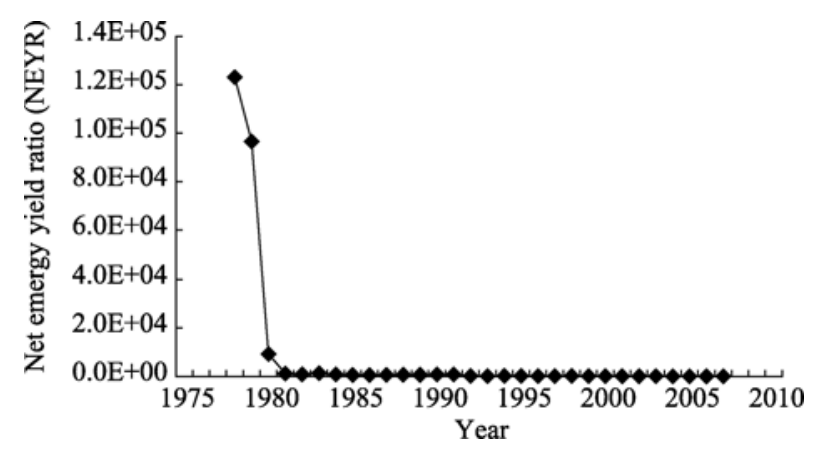

Fig. 5 Trend of the the net emergy yield ratio (NEYR) from 1978 to 2007

Emergy per capita is an index of evaluating the quality of life, which is more scientific and comprehensive than traditional income per capita considering macro eco-economic emergy (Ulgiati et al., 1994; Odum, 1997; Lan, 2002). Restricted by total population and total consumed emergy, the value of emergy per capita increased from $2.45 \times 10^{15} \mathrm{sej} /($ capita.a) to $8.07 \times 10^{15} \mathrm{sej} /($ capita.a) during the period of 1978-2007 (Fig. 6). The reason is that the growing speed of total emergy is faster than that of population. Compared with national level, the emergy per capita rose from $4.22 \times 10^{15} \mathrm{sej} /\left(\right.$ capita.a) to $10.2 \times 10^{15}$ sej/(capita·a) during the period of 1978-2005 (Yang et al., 2010). Compared with developed and other developing countries, such as the USA $\left(41.9 \times 10^{15}\right.$

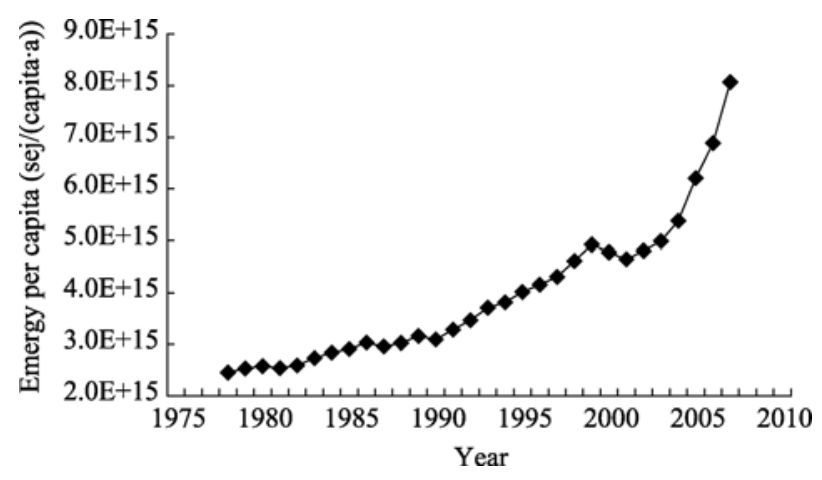

Fig. 6 Trend of emergy per capita from 1978 to 2007 sej/(capita·a)), Italy $\left(22 \times 10^{15} \mathrm{sej} /(\right.$ capita·a $\left.)\right)$, Japan $\left(12.6 \times 10^{15} \mathrm{sej} /(\right.$ capita $\left.\cdot a)\right)$, India $\left(1.0 \times 10^{15} \mathrm{sej} /(\right.$ capita·a $\left.)\right)$, Thailand $\left(3.2 \times 10^{15} \mathrm{sej} /(\right.$ capita.a) $)$ and the average of World (3.86 $\times 10^{15} \mathrm{sej} /($ capita·a)) (Jiang et al., 2008), emergy per capital in Gansu is less than those of the developed countries but higher than the developing countries and world average, which suggests a relatively low level of life quality in Gansu.

We also evaluated emergy density of the region. The emergy density reflects the characteristics of economic development density and grade (Brown and Buranakarn, 2003; Cao and Feng, 2007). Highly industrialized countries usually have high emergy density (Jiang et al., 2008). In Gansu province, emergy density increased from $1.01 \times 10^{17} \mathrm{sej} / \mathrm{km}^{2}$ in 1978 to $4.65 \times 10^{17} \mathrm{sej} / \mathrm{km}^{2}$ in 2007 (Fig. 7). According to the partition standards of Odum (Odum, 1996), and comparing information about emergy analysis in China and other countries (Yan and Odum, 1998), the emergy density of Gansu means the economic development intensity is at a low level nationally.

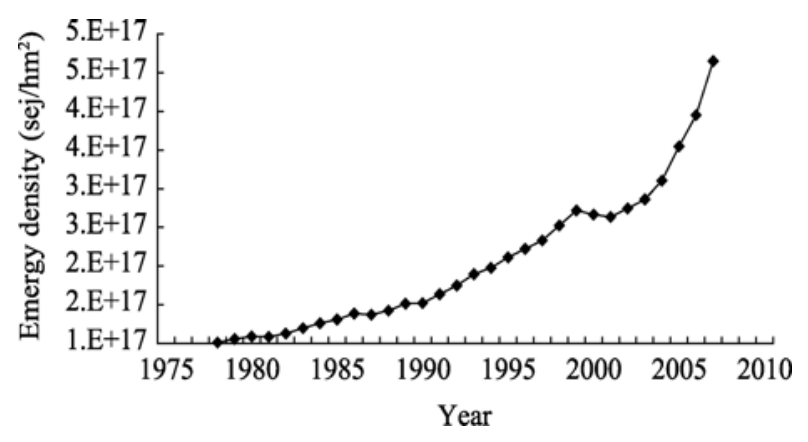

Fig. 7 Trend of emergy density from 1978 to 2007

The ratio of emergy to currency is the ideal scale to evaluate the economy on a macro level. The index is often used to measure economic circumstances, information, commodity and labor force (Ulgiati et al., 1994; Odum, 1997; Lan, 2002). Developing countries have a higher emergy/dollar ratio than developed countries. In developing country, the economy involves more on the use of environmental resources without money exchange. Thus, one dollar in these countries can buy more real commodity than that in developed countries. During the period of 1978-2007, the ratio of emergy to currency in Gansu descended from $7.08 \times 10^{13}$ sej/Chinese Yuan to $7.82 \times 10^{12}$ sej/Chinese Yuan because of a rapid increase in GDP 
development (Fig. 8). The ratio is still higher in Gansu province than in other provinces. These results suggest that the emergy of economic activities in the region was largely depend on natural resources and free natural ecosystem service. The region is lack on transportation, fast currency flow and materials.

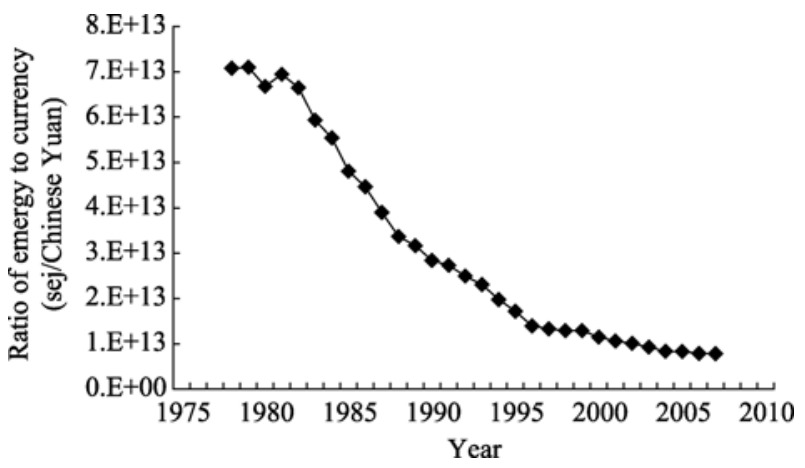

Fig. 8 Trend of ratio of emergy to currency from 1978 to 2007

\section{Conclusion}

This paper is an integrated study on the eco-economic system of Gansu province based on emergy synthesis theory. It provides a sustainable analysis for the regional eco-economic system considering climatic, social, economic and demographic dimensions. During the period of 1978-2007 in Gansu province, the total emergy used increased from $4.58 \times 10^{22}$ sej to $2.11 \times 10^{23}$ sej with annual growth rate of $5.41 \%$, and the renewable emergy flow basically remains steady state, but the nonrenewable emergy flow shows an average annual growth rate of $8 \%$. An original export

\section{References}

An S Q, Bao H S, Zou C J. Studies of emergy flow in a compound agro-ecosystem in the Taihu Lake area, Jiangsu Province, China. Ecological Engineering, 1998, 11: 303-313.

Bartoszczuk P, Nakamori Y. Complex eco-economy system. Journal of Systems Science and Complexity, 2003, 16: 2-4.

Brown M T, Ulgiati S. Emergy evaluation of the biosphere and natural capital. Ambio, 1999, 28: 486-493.

Brown M T, Ulgiati S. Energy quality, emergy, and transformity: H.T. Odum's contributions to quantifying and understanding systems. Ecological Modelling, 2004, 178: 201-213.

Cao K, Feng X. Distribution of emergy indices and its application. Energy \& Fuels, 2007, 21(3): 1717-1723. emergy suggests the economy of Gansu is on a quite adverse and passive position in international competition. A long-range variation trend of environmental loading ratio indicates that the economic activity is giving a high pressure to the environment. The conflict between economic development and environmental protection deteriorates rapidly. Therefore, to develop a circular economy that aims to ease the pressure between use of resources and protection of environment is the direction and inevitable choice for Gansu province's sustainable development. We suggest that an effective population control is also necessary and beneficial to a coordinated and sustainable development of economy, society, resources and environment.

The systematic viewpoint and emergy-based method are significant and effective in understanding the operation and development of the regional eco-economic system. Through an integrated analysis of the total resources, both environment and economy, the outcome of this study yields valuable insight into the use of natural resources. The results could help to determine proper policies for sustainable development in the region.

\section{Acknowledgements}

This study is funded by the Natural Science Foundation of China (40871061), Initial Fund for Doctors of Institute of Applied Ecology at Chinese Academy of Sciences (Y0SBS161S3), 100 Talents Program of the Chinese Academy of Sciences (08YBR111SS), Shenyang Bureau of Science and Technology (1091147-9-00), and Natural Science Foundation of Liaoning province (20092078).

Chen D, Chen J, Luo Z H, et al. Emergy evaluation of the natural value of water resources in Chinese rivers. Environmental Management, 2009, 44: 288-297.

Gansu Yearbook Editorial Board. Gansu Statistical Yearbooks. Beijing: China Statistics Press, 1978-2009.

Huang S L, Odum H T. Ecology and economy-emergy synthesis and public-policy in Taiwan. Journal of Environmental Management, 1991, 32: 313-333.

Jiang M M, Zhou J B, Chen B, et al. Emergy-based ecological account for the Chinese economy in 2004. Communications in Nonlinear Science and Numerical Simulation, 2008, 13: 2337-2356.

Kang D, Park S S. Emergy evaluation perspectives of a multipurpose 
dam proposal in Korea. Journal of Environmental Management, 2002, 66: 293-306.

Lan S F. Emergy Analysis of Eco-economic System. Beijing: Chemical Publishing Company, 2002. 77-95.

Li Z, Yang Y, Liu Y X. Difference among the growth of GDP and urbanization of the provinces and the cities in west China since the reform and opening-up. China Population, Resources and Environment, 2008, 18: 19-26.

Lv C M, Wu Z N. Emergy analysis of regional water ecological-economic system. Ecological Engineering, 2009, 35: 703-710.

Ma J Z, Wang X S, Edmunds W M. The characteristics of ground-water resources and their changes under the impacts of human activity in the arid Northwest China-a case study of the Shiyang River basin. Journal of Arid Environments, 2005, 61: 277-295.

National Bureau of Statistics of China. Comprehensive Statistical Data and Materials on 50 Years of New China (Gansu, 1949-1999). Beijing: China Statistics Press. 2000.

Odum H T. Self-organization, transformity and information. Science, 1988, 242: 1132-1139.

Odum H T. Environmental Accounting: Energy and Environmental Decision Making. New York: John Wiley and Sons Inc., 1996.
120-184.

Odum H T. Emergy definition-reply. Ecological Engineering, 1997, 9: 215-216.

Odum H T, Odum E C. The prosperous way down. Energy, 2006, 31: 21-32.

Patten B C. Energy, emergy and environs. Ecological Modelling, 1992, 62: 29-69.

Ulgiati S, Brown M T. Emergy and ecosystem complexity. Communications in Nonlinear Science and Numerical Simulation, 2009, 14: 310-321.

Ulgiati S, Odum H T, Bastianoni S. Energy use, environmental loading and sustainability - an energy analysis of Italy. Ecological Modelling, 1994, 73: 215-268.

Yan M C, Odum H T. A study on emergy evaluation and sustainable development of Tibetan eco-economic system. Journal of Natural Resources, 1998, 13: 116-125.

Yang Z F, Jiang M M, Chen B, et al. Solar emergy evaluation for Chinese economy. Energy Policy, 2010, 38: 875-886.

Zhang Y, Yang Z F, Yu X Y. Evaluation of urban metabolism based on emergy synthesis: a case study for Beijing. Ecological Modeling, 2009, 220: 1690-1696.

\section{International Center for Arid Land Ecology was established by Xinjiang Institute of Ecology and Geography, CAS and University of California, Riverside, USA}

Invited by Xinjiang Institute of Ecology and Geography, Professor Charles Lois, the vice chancellor of University of California, Riverside, USA, with his colleagues, visited the Institute and went to National Fukang Ecosystem Observation Station of the Institute to have a survey and communication with the researchers.

In order to strengthen the cooperation with developed countries, such as USA, to improve the innovative ability of the Institute, to fulfill the objectives of innovation and to promote the researches of inland river basins in arid land and global climate change, the Institute and University of California, Riverside, by many times of discussion, determined to establish the International Center of Arid Land Ecology. Recently, the vice chancellor and the Institute signed a memorandum of comprehensive cooperation, and held an opening ceremony of the Center.

The main purpose of the Center is to strengthen and promote the joint research and academic communication in the fields of arid land ecology and environmental sciences, to carry out the joint research of inland river basins and global climate change, to construct innovative groups of arid land ecology.

In order to develop and implement scientific-technologic cooperation and research effectively, the Memorandum of Understanding was signed, the Director-General of the Institute, Professor Chen Xi as the director of the Center, and Professor Larry Li of University of California, Riverside, USA, and Professor Li Yan, the director of National Fukang Ecosystem Observation Station of the Institute, as the executive directors of both parties, respectively. 